\title{
As ideias de bioma, biodiversidade, flora e fauna a partir da carta de Pero Vaz de Caminha: uma pratica interdisciplinar entre literatura, biologia, geografia e cultura na formação inicial e continuada de professores
}

The ideas of bioma, biodiversity, flora and fauna from the letter of Pero Vaz de Caminha: an interdisciplinary practice between literature, biology, geography and culture in the initial and continued teacher training

Las ideas de biomasa, biodegradabilidad, flora y fauna a partir de la carta de Pero Vaz de Caminha: una practica interdisciplinar entre literatura, biología, geografía y cultura en la formación inicial y continuada de profesores

\section{Camila Oliveira Lourenço}

Pós-graduanda, UFLA, Brasil. camila_olourenco@hotmail.com

Antonio Fernandes Nascimento Junior Professor Doutor, UFLA, Brasil. toni_nascimento@yahoo.com.br 


\section{RESUMO}

Este trabalho relata uma atividade desenvolvida no ano de 2017 com estudantes em processo de formação inicial e professores em formação continuada integrantes do Programa Institucional de Bolsas de Iniciação à Docência (PIBID), subprojeto Biologia. A atividade teve como objetivo compreender qual o diálogo existente entre a literatura e o Ensino de Ciências. Para a compreensão deste diálogo foi realizado um minicurso na Universidade Federal de Lavras (UFLA), Lavras- MG utilizando a carta de Pero Vaz de Caminha. Após o desenvolvimento da atividade foi pedido para que os participantes discutissem em forma de relato sobre o diálogo existente entre a carta de Pero Vaz de Caminha e o Ensino de Ciências. Posteriormente, os relatos foram analisados por meio da pesquisa qualitativa, análise de conteúdo e categorização das falas. Por meio da análise pode-se identificar temas marcantes nas falas dos participantes envolvendo as questões biológicas, questões pedagógicas e questões culturais que permeiam a carta. Portanto, pode-se concluir a importância da construção de práticas e atividades que atuem no processo de formação de professores a fim de promover uma formação com uma visão holística acerca dos conteúdos que permeiam as diversas áreas do conhecimento. Percebeu-se a relevância da carta como meio para trabalhar as diversas áreas do conhecimento de forma interdisciplinar. Pode-se identificar uma perspectiva transversal, uma vez que a carta apresenta elementos que caracterizavam a cultura indígena. Além disso, percebe-se o documento como recurso interessante, pois promove uma interpretação da natureza, a qual podemos partir para abordar os conhecimentos científicos.

PALAVRAS-CHAVE: Ensino de Ciências. Interdisciplinaridade. Formação de professores.

\section{SUMMARY}

This paper reports an activity carried out in 2017 with students in the initial training process and teachers in continuing education who are part of the Institutional Program of Initiatives for Teaching (PIBID), Biology subproject. The aim of the activity was to understand the dialogue between literature and the teaching of science. In order to understand this dialogue, a mini-course was carried out at the Federal University of Lavras (UFLA), Lavras-MG using Pero Vaz de Caminha's letter. After the development of the activity, participants were asked to discuss the dialogue between Pero $V a z$ de Caminha's letter and Science Teaching. Subsequently, the reports were analyzed through qualitative research, content analysis and categorization of speeches. Through the analysis one can identify important themes in the speeches of the participants involving the biological questions, pedagogical questions and cultural questions that permeate the letter. Therefore, it is possible to conclude the importance of the construction of practices and activities that act in the process of teacher training in order to promote a formation with a holistic vision about the contents that permeate the several areas of knowledge. The relevance of the letter was perceived as a way to work the various areas of knowledge in an interdisciplinary way. A transversal perspective can be identified, since the letter presents elements that characterized the indigenous culture. In addition, the document is perceived as an interesting resource, because it promotes an interpretation of nature, which we can use to approach scientific knowledge.

KEY WORDS: Science Teaching. Interdisciplinarity. Teacher training.

\section{RESUMEN}

Este trabajo relata una actividad desarrollada en el año 2017 con estudiantes en proceso de formación inicial y profesores en formación continuada integrantes del Programa Institucional de Becas de Iniciación a la Docencia (PIBID), subproyecto Biología. La actividad tuvo como objetivo comprender cuál es el diálogo existente entre la literatura y la Enseñanza de Ciencias. Para la comprensión de este diálogo se realizó un minicurso en la Universidad Federal de Lavras (UFLA), Lavras-MG utilizando la carta de Pero Vaz de Caminha. Después del desarrollo de la actividad fue pedido para que los participantes discutieron en forma de relato sobre el diálogo existente entre la carta de Pero Vaz de Caminha y la Enseñanza de Ciencias. Posteriormente, los relatos fueron analizados por medio de la investigación cualitativa, análisis de contenido y categorización de las palabras. Por medio del análisis se pueden identificar temas marcados en las palabras de los participantes involucrando las cuestiones biológicas, cuestiones pedagógicas y cuestiones culturales que permean la carta. Por lo tanto, se puede concluir la importancia de la construcción de prácticas y actividades que actúan en el proceso de formación de profesores a fin de promover una formación con una visión holística acerca de los contenidos que permean las diversas áreas del conocimiento. Se percibió la relevancia de la carta como medio para trabajar las diversas áreas del conocimiento de forma interdisciplinaria. Se puede identificar una perspectiva transversal, una vez que la carta presenta elementos que caracterizaban la cultura indígena. Además, se percibe el documento como recurso interesante, pues promueve una interpretación de la naturaleza, la cual podemos partir para abordar los conocimientos científicos.

PALABRAS CLAVE: Enseñanza de Ciencias. Interdisciplinariedad. Formación de profesores. 


\section{INTRODUÇÃO}

O processo de formação de professores vem sofrendo transformações em sua forma desde o século XX por meio de diversos documentos que permeiam a educação no Brasil como as Leis de Diretrizes e Bases da Educação (LDB, 1996) e Diretrizes Curriculares Nacionais, porém, mesmo com uma série de mecanismos legais e discussões realizadas acerca deste tipo de formação, ainda nos deparamos com o mesmo modelo do início do século XX, modelo este que prioriza a formação específica da área em detrimento da formação pedagógica nos cursos de licenciatura (GATTI, 2010).Além desse fator, a mesma autora aborda que há diversas outras problemáticas relacionadas ao currículo dos cursos de formação de educandos que influenciam na preparação precária para o exercício do magistério. Dentre elas podemos destacar um distanciamento entre o projeto pedagógico dos cursos e a estrutura das disciplinas e suas propostas, pois não é possível identificar uma articulação entre as disciplinas específicas da área de conhecimento e de formação pedagógica e ainda as disciplinas referentes aos conteúdos pedagógicos apresentam alta taxa de ausência dos alunos matriculados.

Pimenta (1999), também trata das dificuldades encontradas com relação ao processo de formação inicial e continuada de professores, argumentando sobre o distanciamento do currículo de conteúdos e das atividades de estágio em relação à realidade escolar, além disso, os cursos de formação continuada se prestam a realizar uma atualização dos conteúdos, em contrapartida perde-se a oportunidade de que o docente faça reflexão sobre sua própria prática. Neste sentido, Gatti (2010), propõe realizar uma revolução nos currículos dos cursos de licenciatura. Além disso, a autora sugere pensar a formação de professores sem partir apenas das ciências e de seus campos disciplinares, mas também das questões pedagógicas que envolvem o ensino a fim de pensar na formação docente em consonância com o contexto da escola. Pimenta (1999) ainda propõe promover a formação inicial e continuada de professores como ponto de partida para uma formação docente de qualidade, permitindo ao professor construir novos saberes e novas práticas a partir de uma reflexão contínua sobre sua ação.

Percebendo e analisando as problemáticas encontradas em relação a formação de professores e, partindo do pressuposto de que é necessário construir atividades a fim de atuar neste tipo de formação para trilhar novos caminhos no que diz respeito a revolucionar as estruturas fragmentadas do preparo docente, foi realizado um minicurso com atuação na formação inicial e continuada de professores de ciências e biologia.

O minicurso foi elaborado para os alunos do curso de Licenciatura em Ciências Biológicas, da Universidade Federal de Lavras (UFLA- MG) e para professores supervisores de escolas estaduais e municipais de Lavras - MG, ambos, integrantes do Programa Institucional de Bolsas de Iniciação à Docência (PIBID- Biologia) da UFLA. A atividade contou com a apresentação da Carta de Pero Vaz de Caminha, obra literária que retrata a chegada dos portugueses em terras brasileiras, e exposições de algumas imagens, pinturas e poemas que se relacionam com a temática da carta. Neste sentido, o objetivo do trabalho foi identificar o diálogo existente entre a literatura e o ensino de ciências na formação inicial e continuada de professores.

\section{METODOLOGIA}

Para a aplicação e construção do trabalho foi utilizada a metodologia de pesquisa qualitativa, que conforme Minayo (2009), é uma pesquisa que se preocupa com um nível de realidade que não pode ser quantificado, partindo de questões amplas e que vão se definindo com o desenvolver do estudo, segundo Godoy (1995). Além disso, ainda de acordo com a autora, a 
pesquisa qualitativa, que também pode ser identificada como pesquisa de campo ou naturalística, é um tipo de estudo que parte de dados descritivos para explicar a realidade em que um sujeito está inserido. Neste sentido, o pesquisador se torna um instrumento fundamental para a coleta de dados, colocando-se no lugar do sujeito para que possa identificar e posteriormente interpretar sua realidade e assim o ambiente natural se configura como fonte direta de dados (GODOY, 1995).

Dentre as diversas técnicas encontradas na pesquisa qualitativa a análise de conteúdo foi utilizada neste trabalho. Esta como recurso metodológico se torna essencial, pois uma vez que o conteúdo pode ser transformado em texto é possível realizar análises por meio desta técnica. Seu objetivo principal é a manipulação de mensagens que pode ser pelo conteúdo ou pela expressão deste conteúdo, conforme Oliveira (2008). Além disso, Bardin (1979) traz que ela permite ao pesquisador realizar uma descrição sistemática e objetiva do conteúdo apresentado pelas falas dos participantes, analisando o conteúdo de forma quantitativa e qualitativa. As falas dos participantes foram transcritas e posteriormente identificadas pela letra $A$, para os alunos dos cursos de licenciatura em Ciências Biológicas, seguida de uma numeração e os professores participantes foram identificados pela palavra professor, seguido de numeração.

Como procedimento metodológico foi utilizado a categorização. Este método permite realizar uma classificação dos elementos contidos nas falas por meio da diferenciação e posterior reagrupamento destas, partindo de critérios que se relacionem com o conteúdo e o objetivo apresentado pelo projeto (BARDIN, 1979) e (MINAYO, 2009). Para Oliveira (2008), as categorias são classes que tem por função reunir os elementos, criando uma nomenclatura genérica para sua representação, assim é imposta pelo pesquisador uma nova forma de organização das mensagens produzidas pelos sujeitos participantes do estudo em questão a fim de re-apresentar o objeto de estudo. Neste processo de categorização das falas cada categoria foi representada por elementos do discurso dos participantes com o intuito de exemplificar e discutir cada tema que se relacionava como o objeto de estudo.

\section{RESULTADOS E DISCUSSÃO}

\section{Preparação e Relato do Minicurso:}

A atividade foi desenvolvida em dois momentos:

Momento 1 - O primeiro momento foi direcionado para o reconhecimento da carta de Pero Vaz de Caminha (Descobrimento do Brasil), a fim de identificar os conhecimentos prévios dos participantes com relação à carta e abordar seus aspectos essenciais para debruçarmos sobre ela e então reconhecer os conceitos e conteúdos que podem ser extraídos e trabalhados com os alunos da Educação Básica.

Inicialmente foi realizado questionamentos sobre o conhecimento dos participantes com a obra e o contexto em que ela foi produzida. A maioria dos bolsistas não obtiveram contato com o documento em momentos anteriores ao minicurso e então foram trazidos alguns aspectos da 
carta como, o contexto em que foi produzida, o autor do documento e a linguagem utilizada por ele, assim pode-se abordar elementos da personalidade de Pero Vaz de Caminha, autor da carta, abordar o momento histórico ao qual Portugal estava inserido e tratar sobre o Português Arcaico, língua utilizada pelos portugueses no momento de redescobrimento do Brasil.

Após este momento a turma foi dividida em quatro grupos para que pudessem realizar a leitura de partes da carta de Pero Vaz de Caminha (http://docente.ifrn.edu.br/paulomartins/livroscassicos-de-literatura/a-carta-de-pero vaz-de-caminha-em-pdf). 0 documento foi dividido em quatro partes, então o grupo 1 ficou responsável pela leitura das páginas 2,3 e 4, o grupo 2 pelas páginas 5,6 e 7, o grupo 3 pelas 8,9 e 10 e o grupo 4 pelas 11,12,13 e 14. Posteriormente ao momento de leitura foi pedido para que os participantes discutissem em grupo quais os conceitos biológicos e não biológicos que poderiam ser trabalhados a partir da obra e após esse momento apresentaram a parte da carta lida e relataram os assuntos discutidos pelo grupo.

Neste momento, o primeiro grupo trouxe a questão da chegada dos portugueses no Brasil, retratando o momento em que eles avistaram terras brasileiras e ainda a forma com que eles abordaram a população indígena presente na região. Além disso, foi abordada a questão de como os portugueses percebiam os índios e os descreviam e então este grupo citou que podiam ser trabalhados temas como o vestuário indígena, as formas de comunicação entre indígenas e portugueses e a visão que a população portuguesa apresenta da população nativa.

O segundo grupo trouxe questões sobre a descrição de algumas espécies de fauna e flora relatadas na carta, a exploração indígena por parte dos portugueses, a inserção da religião na cultura indígena e os instrumentos utilizados pelos indígenas. Assim, os participantes perceberam a relevância de se trabalhar os conteúdos de história e literatura de forma interdisciplinar e os instrumentos indígenas para falar dos esportes e a expressão corporal, percebendo o ritual indígena como uma dessas expressões. Também perceberam a importância de trazer questões sobre diversidade de espécies e o bioma brasileiro.

O terceiro grupo trouxe questões sobre a descrição das diversidades encontradas e relatadas por Pero Vaz de Caminha, além de abordar a cultura indígena percebida através da leitura da carta. Os participantes compreenderam a importância de se trabalhar os temas também de forma interdisciplinar, explorando as disciplinas de história, biologia, geografia e português (linguagem).

O quarto grupo trouxe a questão do choque cultural na relação entre os indígenas e os portugueses presente na carta e a presença da diversidade de espécies percebidas a partir do relato. Os participantes consideraram relevante abordar a questão da interferência da cultura europeia na cultura indígena, além da biodiversidade de organismos presentes no relato da carta de Pero Vaz de Caminha.

Momento 2 - No segundo momento foi realizada uma exposição no MHN (UFLA) para o aprofundamento dos elementos trazidos pela carta de Pero Vaz de Caminha. Este momento foi pensado com o intuito de fazer com que os professores e alunos presentes realizassem uma viagem pela história do descobrimento do Brasil, caracterizando o momento pré e póscolonização por meio dos elementos expostos durante o minicurso, reconhecendo a cultura indígena, pinturas, poemas e imagens que se relacionam com a carta. 
A exposição dos materiais ocorreu por meio de questões norteadoras. Estas foram: Quais os motivos para que os portugueses desbravassem os oceanos?; Quais instrumentos no processo de navegação? Apresentação das imagens; O que os portugueses buscavam? Por onde passaram? Como chegaram em terras brasileiras?; O que os portugueses encontraram nestas terras?.

Durante estas questões a prelecionista apresentou alguns recursos com o intuito de introduzir e discutir os assuntos propostos, estes estão representados no quadro (Quadro 1).

Quadro 1: Discussão dos assuntos através do uso de recursos

\begin{tabular}{|c|c|}
\hline Questões Norteadoras & Recursos \\
\hline - Quais os motivos para desbravar os oceanos? & Mapa Mundí / Poema “Mar Português" (Fernando \\
Pessoa)
\end{tabular}

Foram discutidos os motivos que levaram os portugueses a desbravarem os oceanos, abordando um pouco da história, economia, localização geográfica do país, que contribuiu para o favorecimento do processo de navegação e as dificuldades encontradas pelos portugueses com a saída de seu país. Também foram apresentados os instrumentos utilizados nas navegações, abordando suas funções e finalidades, desse modo foi possível perceber as tecnologias da época e a importância delas para o encontro das terras brasileiras. A busca por ouro e especiarias foi outro assunto tratado durante o minicurso, abordando a motivo de suas buscas, pois o ouro servia como moeda confiável de troca e as especiarias para a conversação dos alimentos, além disso foi falado sobre as regiões as quais as navegações perpassaram com o intuito de descobrir uma terra nova.

A chegada dos portugueses em terras brasileiras foi caracterizada por pinturas que representavam este momento, por meio destas foi possível identificar as embarcações que os portugueses utilizavam, a vegetação presente e a população presente na região, o processo de catequização dos indígenas e as diferenças entre a cultura europeia e a cultura indígena. Além disso, foi possível trazer pinturas que foram produzidas a partir da carta por alguns pintores da época e trazer o contexto em que elas foram produzidas. A cultura indígena foi outro tema trabalhado no minicurso, para esse momento foram trazidas pinturas que representa os índios e demonstravam os adereços utilizados por eles, poemas que abordam a questão indígena e os alguns artefatos indígenas, como os arcos e flechas, cestos e o grafismo indígena. Assim foi 
abordado sobre a forma de sobrevivência e subsistência do povo indígena, as diferentes tribos indígenas e os materiais utilizados para a produção de cestarias e outros artefatos. Por meio do poema Canção do Exílio de Gonçalves Dias, foi possível abordar a fauna e flora presente no Brasil e então os participantes puderam perceber o ambiente o qual os portugueses se depararam quando chegaram nas terras que seriam chamadas de Brasil.

Ao término da atividade foi discutido sobre a importância do relato de Pero Vaz de Caminha para o reconhecimento da história do Brasil, trazendo a questão da minuciosidade no momento de escrita, o que permite imaginar o ambiente e os acontecimentos da época de forma clara.

Posteriormente a construção da aula pelos participantes foi pedido para que eles discutissem as possibilidades de diálogo entre o ensino de ciências e a carta de Pero Vaz de Caminha.

Os resultados foram obtidos a partir do relato escrito dos professores e alunos do Programa Institucional de Bolsas de Iniciação à Docência (PIBID - Biologia). As falas dos professores em exercício foram analisadas a partir dos conteúdos presentes, conforme a questão colocada durante o minicurso. Já as falas dos estudantes em processo de formação foram analisadas por meio da análise de conteúdo e categorização (Quadro 2). Os professores foram identificados com a letra " $\mathrm{P}$ " seguida de uma numeração e os alunos em formação foram identificados com a letra " $A$ " seguida de numeração para identificação dos participantes.

Quadro 2: Análise das falas dos alunos do programa

\begin{tabular}{|c|c|c|c|}
\hline Categoria & Descrição & Frequência & Ocorrência \\
\hline Conceitos Biológicos & $\begin{array}{l}\text { Aqui encontram-se as falas dos } \\
\text { participantes que identificaram } \\
\text { temas relacionados as questões } \\
\text { biológicas e que reconhecem a } \\
\text { possibilidade de se trabalhar com } \\
\text { elas a partir da carta, destacando } \\
\text { como temáticas a serem } \\
\text { trabalhadas o Bioma, a } \\
\text { Biodiversidade, a Fauna e Flora. }\end{array}$ & 17 & $\begin{array}{c}\text { A2, A3, A4, A5, A6, A7, } \\
\text { A9, A10, A11, A13, A14, } \\
\text { A16, A17, A19 A20, A22, } \\
\text { A23 }\end{array}$ \\
\hline Práticas pedagógicas & $\begin{array}{l}\text { As falas presentes nesta categoria } \\
\text { tratam da presença dos temas } \\
\text { transversais e da possibilidade de } \\
\text { se trabalhar com eles a partir da } \\
\text { carta, além da oportunidade de } \\
\text { uma prática interdisciplinar a } \\
\text { partir da obra de Pero Vaz de } \\
\text { Caminha. }\end{array}$ & 12 & $\begin{array}{l}\text { A1, A5, A6, A7, A13, A14, } \\
\text { A15, A16, A18, A19, A21, } \\
\text { A22 }\end{array}$ \\
\hline Questões Culturais & $\begin{array}{l}\text { Esta categoria reúne as falas dos } \\
\text { alunos que abordam presença da } \\
\text { cultura indígena e a forma como } \\
\text { ela pode ser discutida por meio da } \\
\text { carta. }\end{array}$ & 9 & $\begin{array}{c}A 2, A 3, A 4, A 6, A 8, A 11 \\
A 15, A 19, A 20\end{array}$ \\
\hline
\end{tabular}




\section{Discussão}

A partir da questão discutida pelos professores em formação continuada e pelos alunos em formação inicial foi possível perceber a possibilidade de trabalhar com a Biodiversidade, Bioma, a fauna e flora brasileiras descritas por Pero Vaz de Caminha. Assim, entende-se as possibilidades da carta no trabalho com temas e conceitos biológicos, permitindo uma reflexão na relação entre a literatura e o ensino de ciências.

A literatura se configura como arte e neste sentido se relaciona com a Ciência na medida em que compreendemos essa área sob uma perspectiva dinâmica como a literatura. A Ciência é uma atividade decorrente da atividade social complexa e está impregnada de concepções estéticas, históricas, sociais e morais como a Literatura. Além disso, a Ciência não é vista como acabada e a arte não como um processo sem método. Neste sentido, é possível perceber a Ciência como uma obra aberta, pois é produzida por uma comunidade científica. Assim, ao tratar a Ciência como obra aberta, o cientista permite ao literato várias possibilidades de leitura (SILOCHI, 2014).

Ainda de acordo com a autora, a utilização de uma linguagem não acessível pela comunidade científica leva a uma dificuldade de interpretação dos conceitos científicos por parte dos estudantes e então trabalhar com textos literários auxilia nessa dificuldade, pois uma narrativa literária transforma as informações científicas em uma linguagem simples. Além disso, a iniciativa de unir Ciência e Literatura pode levar a uma reflexão do papel científico na sociedade, uma vez que se insere no contexto da escola e apresentar leituras diferentes do conhecimento científico permite a construção de conhecimentos de forma articulada e não fragmentada (SILOCHI, 2014), porém a organização dos conteúdos científicos e as metodologias empregadas fica a cargo do professor e neste sentido é necessário que os cursos de formação de professores apresentem boas condições para a atuação desses docentes.

A literatura então nos permite identificar conceitos e conteúdos científicos de forma mais lúdica, facilitando o processo de ensino e aprendizagem desses temas. Desta forma, os textos literários permitem instigar a abordagem de conteúdos biológicos, o que podemos perceber no trabalho com a carta de Pero Vaz de Caminha. Isso se torna interessante, pois além do contato com a literatura é importante que os alunos e os professores se apropriem dos conhecimentos científicos, uma vez que ele é propriedade de toda a humanidade e sua linguagem deve informar a todos os indivíduos para compreensão deste tipo de conhecimento (GALLIANO, 1986), porém é necessário que haja uma instrumentalização e é neste sentido que se torna interessante a possibilidade de trabalhar com os conhecimentos biológicos, como a Biodiversidade, Bioma, Fauna e Flora, pois ele faz parte dos conhecimentos produzidos pela ciência e a partir de seu caráter informativo, ainda segundo Galliano (1986), ela apresenta como propósito desvendar a realidade e a partir disso se torna possível ao homem transformar a sociedade em que vive por meio do reconhecimento deste tipo de conhecimento.

A interdisciplinaridade também foi colocada como aspecto que permite o diálogo entre a literatura e o ensino de ciências. Os professores argumentaram sobre a possibilidade de se trabalhar com temas relacionados à Geografia, História, Matemática, Física e Educação Física. Todas estas áreas correspondem a ciências e neste sentido, Galliano (1986) argumenta que elas podem se relacionar entre si por meio de fatos, processos e estruturas de qualquer nível da 
realidade objetiva para a reconstrução das diferentes relações entre os fatos e seus distintos aspectos.

Segundo Feistel e Maestrelli (2009) há uma necessidade que vêm ganhando força em integrar as mais diversas áreas do conhecimento e contextualizar o ensino de forma mais significativa por meio do que chamamos de interdisciplinaridade, porém ainda é possível perceber uma dificuldade no desenvolvimento de um trabalho interdisciplinar no contexto educacional, tanto na educação básica com no ensino superior.

Ainda segundo as autoras, é necessário caminhar em direção a propostas interdisciplinares cada vez mais contextualizadas, uma vez que os referenciais teóricos e os documentos oficiais nos permitem perceber uma necessidade de discussão e de reflexão sobre a temática nos cursos de formação de professores de Ciências para ultrapassar a organização curricular disciplinar. Neste sentido, se faz relevante uma reflexão sobre a importância dessa temática nos processos e contextos educacionais.

O que devemos considerar é que a configuração de uma prática interdisciplinar protesta contra a fragmentação dos conhecimentos conferidos pelas disciplinas que não interagem, contra a dissociação da vida, percebendo- a como um todo complexo e indissociável e contra o conformismo das situações adquiridas ou ideias impostas. Assim, podemos tratar dos objetivos de processos interdisciplinares que se caracterizam em uma demanda para a construção do fundamento para novas disciplinas, em uma reivindicação da fragmentação dos saberes, em uma preocupação com uma formação profissional que se desvincule da especialização de uma determinada área do conhecimento e em uma demanda social que leva a exigência de temáticas que vão além daqueles colocadas pelas disciplinas já existentes nas universidades (JAPIASSU, 1976).

Podemos perceber que a prática interdisciplinar vem como uma necessidade de produção e socialização dos conhecimentos das mais variadas formas, neste sentido, a finalidade de se trabalhar com ela é a busca por uma superação da fragmentação nos processos construção dos conhecimentos dos mais variados tipos e com os mais variados significados (THIESEN, 2008), porém trabalhar de forma interdisciplinar não é necessariamente reunir as disciplinas, adicionar ou colecionar várias especialidades ou tomar posições teóricas de especialistas que se reúnem sem um objetivo de pesquisa. As atividades interdisciplinares devem despertar o interesse pessoal dos professores e estudantes pela aplicação de sua disciplina a uma outra, estabelecer vínculos mais estreitos entre os conteúdos a serem estudados, abolir o trabalho maçante que algumas disciplinas específicas apresentam, reorganizar o saber, estabelecer a comunicação entre as áreas disciplinares específicas, construir disciplinas e domínios novos de conhecimentos coerentes com a realidade social, aperfeiçoar e reciclar os professores de sua formação especializada e reconhecer o caráter comum de certas problemáticas (JAPIASSU, 1976).

Ainda de acordo com o autor, trabalhar de forma interdisciplinar significa, mesmo com a delimitação de um tema, não abandonar as múltiplas determinações e mediações históricas que o constituem determinados conteúdos, visto que, a interdisciplinaridade se funde no caráter dialético da realidade social, porém, podemos identificar que o movimento de interdisciplinaridade no contexto educacional ainda está se iniciando, embora haja grandes esforços para a inserção deste tipo de movimento nas instituições de ensino (THIESEN, 2008). 
O mesmo autor argumenta que um processo educativo desenvolvido por meio desta perspectiva de interdisciplinaridade possibilita uma compreensão acerca da relação entre teoria e prática, além de contribuir para uma formação crítica e criativa, conferindo ao professor habilidades para enfrentar novos desafios referentes à realidade e aos conhecimentos. Ela ainda impulsiona transformações no pensamento e na ação dos seres humanos, pois permite demonstrar que vivemos em uma teia de interações complexas, podendo compreender que tanto as teorias como os conceitos estão conectados entre si. Além disso, é um movimento que prioriza a problematização, a atitude crítica e reflexiva e então se configura em uma visão articuladora que irá romper com o pensamento disciplinar, fragmentado e hierárquico que constitui o mundo por muito tempo.

A partir do reconhecimento da importância do movimento interdisciplinar, Thiesen (2008), propõe tornar este movimento um elemento orientador na formação de profissionais da Educação, porém o docente necessita apresentar uma visão integrada da realidade e entender uma visão profunda de sua área de formação não é suficiente para promover um processo interdisciplinar.

Portanto, Japiassu (1976) aborda que, os empreendimentos interdisciplinares, tanto do ponto de vista epistemológico quanto do ponto de vista pedagógico, revelam a necessidade de rever e reformular as relações existentes entre as ciências naturais e as ciências humanas, porém, segundo o autor, é necessário não somente reorientar todo o sistema educacional, mas também uma orientação no contexto educacional que permita uma união estreita entre ensino e pesquisa, tendo como base a exploração e resolução de novas problemáticas por meio de uma equipe de profissionais cooperantes.

Também foi possível identificar que os estudantes e professores perceberam a cultura indígena como uma forma de diálogo entre a literatura e o ensino de ciências, uma vez que a carta retrata este tipo de cultura. Assim, por meio da cultura indígena, identifica-se uma nova visão sobre a natureza, diferente da visão científica. Neste sentido, a carta de Pero Vaz de Caminha promove o reconhecimento de uma cultura tradicional por meio de seus costumes, mas também apresenta uma nova forma de perceber a ciência. Além disso, os docentes apontaram a possibilidade de trabalhar com temas transversais, como o tema pluralidade cultural.

Tratando da perspectiva da relação entre a cultura indígena e o Ensino de Ciências, podemos iniciar a discussão argumentando que o homem, desde seus primórdios vem atribuindo símbolos e significados ao mundo, ou seja, produzindo cultura e neste sentido, cada cultura apresenta uma visão da natureza particular (BAPTISTA, 2010). Assim, podemos compreender que existe uma diferença entre a percepção da natureza sobre o olhar científico em relação a visão da natureza das comunidades tradicionais, como a cultura indígena.

De acordo com Diegues e Aruda (2000), as sociedades tradicionais dependem da natureza para a manutenção de seu modo de vida, assim, por meio desta dependência surgem os conhecimentos tradicionais ou locais. Este conhecimento tradicional é definido como o saberfazer a respeito do mundo natural e sobrenatural. Baptista (2010) nos traz que esses conhecimentos são produzidos pelos agricultores, babaçueiros, quilombolas, pescadores, artesãos, indígenas e outros tipos de comunidades, sendo que estes conhecimentos podem ser expressos por meio dos mitos, rituais, práticas e narrações de caráter oral. A ciência perceber a 
natureza como um conjunto de fenômenos que podem ser explicados de forma natural e material, podendo ser testado de maneira objetiva e empírica. Além disso, tendo como propósito desvendar os segredos da realidade, o conhecimento científico os explica de forma clara e precisa, descobre suas relações de predomínio, igualdade e subordinação com outros fatos e fenômenos, conforme Galliano (1986), porém apresenta como base as experiências humanas. Apesar da importância dos dois tipos de conhecimento para a sociedade, cultural e científico, na sala de aula, nos deparamos com a desconsideração dos saberes culturais em detrimento da apresentação dos conhecimentos científicos, segundo Baptista (2010). Neste sentido, o cientificismo leva a uma padronização dos critérios que permitem a validação dos saberes, estes outros tipos de conhecimentos são então desvalorizados. Assim, o Ensino de Ciências deve se desenvolver por meio de uma crítica às construções humanas, sem desprezar a diversidade de saberes existentes e que revelam uma visão do mundo (PAIVA, 2014). Além disso, a abordagem de uma visão puramente científica deve ser evitada quando tratamos dos âmbitos educacionais, pois existem alguns grupos da sociedade, como as comunidades indígenas, que não apresentam a ciência como base para o desenvolvimento das atividades humanas, porém, também se faz necessário apresentar estes conhecimentos tradicionais para indivíduos cujas vidas se pautam no conhecimento científico (PAIVA, 2014).

Dessa forma, é de total relevância que um de formação inicial e continuada tenha contato com temáticas relacionadas a cultura indígena, além dos conhecimentos científicos específicos de sua área para que a abordagem dos conteúdos específicos não sobreponha os conhecimentos tradicionais e para que este tipo de conhecimento possa ser inserido de forma a considerar o contexto dos estudantes.

Outro ponto abordado pelos alunos em formação inicial de professores foi a possibilidade de se trabalhar com o tema transversal Pluralidade Cultural. Conforme os Parâmetros Curriculares Nacionais -PCN: Pluralidade Cultural (BRASIL, 1997), este tema deve ser vivido, ensinado e aprendido sendo que, esse ensino e aprendizagem se configura por meio de um trabalho de construção diária para que possamos nos envolver uns com os outros e assim compreender que sem a participação do outro nada se pode saber.

O documento também aborda os objetivos de se ensinar a temática Pluralidade Cultural que são: reconhecer a diversidade cultural existente em nosso país para compreendê-la como direito dos povos e como um elemento de fortalecimento da democracia, reconhecer a importância destes diferentes tipos de cultura na construção da identidade brasileira, reconhecer as qualidades da própria cultura, repudiar qualquer tipo de discriminação, valorizar as diferentes culturas e compreender a desigualdade social como uma problemática passível de mudança. Assim, cabe às instituições formadoras construir um ambiente de confiança entre os estudantes e professores para que haja a manifestação de características culturais de determinados grupos e estas sejam compreendidas como circunstâncias da vida e como forma de desenvolvimento das potencialidades pessoais dos indivíduos (BRASIL, 1997). 


\section{CONSIDERAÇÕES FINAIS}

O processo de formação de professores, tanto inicial quanto continuada, apresenta problemáticas em seu desenvolvimento. Uma dessas problemáticas é a estrutura fragmentada presente no momento do preparo docente, além do distanciamento do currículo de formação do contexto escolar. Nesta perspectiva, foi possível identificar a importância da construção de práticas e atividades que atuassem nesses processos de formação, como o minicurso construído e relatado neste trabalho, a fim de promover uma formação de docentes com uma visão holística acerca dos conteúdos que permeiam as diversas áreas do conhecimento.

Além de identificar a importância desta atividade, percebeu-se a relevância da carta de Pero Vaz de Caminha como meio para trabalhar com diversas áreas do conhecimento como a Física, Química, Matemática, Geografia, Biologia, Português. Assim, foi possível realizar uma atividade de forma interdisciplinar, o que permite se desvincular das práticas fragmentadas que, na maioria das vezes, podemos perceber nos cursos de formação de professores. Também podese trabalhar com uma perspectiva transversal, uma vez que a carta de Pero Vaz de Caminha apresentava elementos que caracterizavam a cultura indígena da região encontrada pelos portugueses, neste sentido, podemos perceber o tema Pluralidade Cultural como um dos elementos presentes na carta e que foi possível trabalhar durante o desenvolvimento da atividade, assim foi possível atuar na formação de professores, tanto inicial e continuada para que eles possam discutir essas temáticas com seus alunos da Educação Básica, uma vez que os Parâmetros Curriculares Nacionais abordam a temática como importante e necessária nessa etapa de ensino.

Outro ponto possível de ser abordado foram os conhecimentos biológicos relacionados a carta, este se caracteriza como um dos conhecimentos científicos. Neste sentido, pode-se identificar a carta como um recurso interessante, pois promove uma interpretação da natureza, a qual podemos partir para tratar dos conhecimentos científicos. Esse aspecto é interessante, pois tornou-se possível trabalhar a temática com os professores em formação inicial e continuada, sendo estes os responsáveis por instigar os estudantes no interesse e curiosidade pela ciência e ainda organizar atividades que exploram os conhecimentos científicos.

A atividade também se tornou interessante, pois permitiu a construção de conhecimentos acerca da Ciência e das questões pedagógicos que permeiam a prática docente. Além disso, a construção do minicurso promoveu a realização de uma pesquisa extensa sobre os conteúdos de diversas áreas do conhecimento, o que permitiu a construção de uma prática interdisciplinar. Outro ponto interessante da construção do minicurso foi a possibilidade de planejar uma atividade para a formação inicial e continuada de professores e refletir sobre ela durante e após seu desenvolvimento, assim foi possível compreender a importância de uma prática docente reflexiva para atuar e promover um processo de ensino e aprendizagem de qualidade.

\section{AGREDECIMENTOS}

CAPES, FAPEMIG e UFLA 


\section{REFERÊNCIAS BIBLIOGRÁFICAS}

BAPTISTA, Geilsa Costa Santos. Importância da demarcação de saberes no ensino de ciências para sociedades tradicionais. Ciência \& Educação, v. 16, p. 679-694, 2010.

BARDIN, LAURENCE. Análise de conteúdo. Lisboa, Edições 70, 1979.

BRASIL, Lei de Diretrizes e Bases da Educação. Lei n 9.394/96, de 20 de dezembro de 1996.

BRASIL. Secretaria de Educação Fundamental. Parâmetros curriculares nacionais: pluralidade cultural, orientação sexual / Secretaria de Educação Fundamental. - Brasília: MEC/SEF, 1997. 164p.

CAMINHA, Pero Vaz de. Carta de Pero Vaz de Caminha a El-Rei D. Manuel / sobre o achamento do Brasil/ Pero Vaz de Caminha - $2^{\circ}$ ed. - São Paulo: Martin Claret, 2014.

CHAUVIN, Jean Pierre. Carta de Pero Vaz de Caminha a El-Rei D. Manuel I sobre o achamento do Brasil/ Pero Vaz de Caminha - 2 ed. - São Paulo: Martin Claret, 2014.

DIEGUES, Antonio Carlos; ARRUDA, Rinaldo Sergio Vieira; SILVA, Viviane Capezzuto Ferreira da; FIGOLS, Francisca Aida Barboza; ANDRADE, Daniela. Os Saberes Tradicionais e a Biodiversidade no Brasil. São Paulo: USP, 2000.

FEISTEL, Roseli Adriana Blümke; MAESTRELLI, Sylvia Regina Pedrosa. A Interdisciplinaridade na Formação de Professores de Ciências Naturais e Matemática: algumas reflexões. In: ENCONTRO NACIONAL DE PESQUISA EM EDUCAÇÃO EM CIÊNCIAS, 7, 2009, Florianópolis. Anais do VII Encontro Nacional de Pesquisa em Educação em Ciências. Florianópolis/SC: Gráfica Floriprint, 2009. 11 f. v. único.

GALLIANO. A. Guilherme. O método científico: teoria e prática. São Paulo: HARBRA, 1986, $200 \mathrm{f}$.

GATTI, Bernadete Angelina. Formação de professores no Brasil; Características e problemas. Educação e Sociedade (online), v. 31, n. 113, p. 1355-1379. 2010

GODOY, Arilda Schmidt. Introdução à pesquisa qualitativa e suas possibilidades. RAE. Revista de Administração de Empresas, São Paulo, v. 35, p. 57-63, 1995.

JAPIASSU, Hilton. Interdisciplinaridade e a patologia do saber. Rio de Janeiro: Imago, 1976, $111 \mathrm{f}$.

MINAYO, Maria Cecília de Souza. Trabalho de campo: contexto de observação, interação e descoberta. In: MINAYO, M. C. S. (Org.). Pesquisa Social: Teoria, método e criatividade. Petrópolis: Vozes, 2009. p. 30-37.

OLIVEIRA, Denize Cristina de. Análise de Conteúdo Temático-Categorial: uma proposta de sistematização. Revista Enfermagem (UERJ), v. 16, p. 569-576, 2008.

PAIVA, Ayane de Souza. Conhecimentos tradicionais e ensino de biologia: desenvolvimento colaborativo de uma sequência didática sobre reprodução vegetal. 2014. 226 f. Dissertação (Mestrado) - Universidade Federal da Bahia Faculdade de Educação, Salvador, 2014.

PIMENTA, Selma Garrido. Formação de professores: identidade e saberes da docência. In: PIMENTA, Selma Garrido. (Org.). Saberes pedagógicos e atividade docente. São Paulo: Cortez Editora, 1999. p. 15- 34.

SILOCHI, Josiane. Aproximações entre literatura e ciências: um estudo sobre os motivos para utilizar textos literários no Ensino de Ciências. Dissertação apresentada ao curso de Pós-Graduação em Educação em Ciências e em Matemática - Universidade Federal do Paraná. Paraná. 2014. 
THIESEN, Juares da Silva. A interdisciplinaridade como um movimento articulador no processo ensino-aprendizagem. Revista Brasileira de Educação, v. 13, p. 545-554, 2008. 